\title{
Cultura visual y cultura sorda: recursos visuales en programas de enseñanza de lenguas para sordos (xvii-xx)
}

Navarro Rincón Antonia anavarro@ugr.es

Universidad de Granada, España

\section{Reference}

Antonia, Navarro Rincón; (2012) "Cultura visual y cultura sorda: recursos visuales en programas de enseñanza de lenguas para sordos (xvii-xx)", p. 98-102 . In: Barbosa, Helena; Quental, Joana [Eds]. Proceedings of the 2nd International Conference of Art, Illustration and Visual Culture in Infant and Primary Education. São Paulo: Blucher, 2015. ISSN 2318-695X, ISBN: 978-989-98185-0-7

DOI 10.5151/edupro-aivcipe-20

Esta comunicación desarrolla un estudio sobre la importancia de los recursos didácticos visuales en la apropiación de las lenguas y culturas de las comunidades a las que pertenecen los niños sordos en tanto que miembros biculturales y bilingües de esa sociedad. Presenta un recorrido a través de programas de enseñanza de lenguas para personas sordas publicados en España y Francia, entre los siglos xvii y xx, con el fin de dar a conocer las tradiciones, innovaciones, ruptura y continuidad en el empleo de diferentes recursos visuales cuya presencia/ausencia está asociada a prácticas metodológicas educativas, constituyéndose en referentes universales de la lengua y cultura sorda. El estudio pretende contribuir a la recuperación de la memoria del patrimonio educativo y cultural de estas personas como paso previo a la creación y adaptación de recursos didácticos visuales que posibiliten la adquisición de las lenguas que configuran su identidad.

This article is related to the study on the importance of visual didactic resources regarding the appropriation of languages and cultures where deaf children and bicultural and bilingual members from that society take part. It presents a analysis of language teaching programs for deaf people, published in Spain and in France between 17th century and 2oth century in order to announce the traditions, innovations, breaking-off, and continuation in the use of the different visual resources, presents or absents in the different educational methodologies and which have been constituted as universal references of the deaf language and culture The aim of this paper is to contribute to recover the educational heritage memory as a previous step for the creation and adaptation of visual didactic resources which enable deaf children to acquire the languages which form their identity.

Keywords visual culture, deaf people, language teaching

\section{Introducción}

Aunque el impacto de las NTIC en todos los ámbitos de la sociedad ha constituido una verdadera revolución cultural, en la primera década del siglo XXI se han sucedido otros acontecimien tos de especial relevancia para las comunidades sordas europeas que han visto reconocer y legalizar sus lenguas de signos, con las consecuencias que ello tendrá en los distintos ámbitos de las relaciones sociales, culturales y educativas. El impulso del Consejo de Europa en 2001 con la publicación del Marco europeo común de referencia para las lenguas no solo ha establecido unos niveles comunmente aceptados en cuanto al dominio de las lenguas y culturas sino que, entre otras cuestiones, ha servido para dar cabida a todas y cada una de ellas, sin excepción. En este contexto de ciudadanía europea cabe plantearse como 
$2^{\text {nd }}$ International Conference Art, Illustration and Visual Culture in Infant and Primary Education $2^{\circ}$ Congresso Internacional

de Arte, llustracão e Cultura Visual

na Educação Infantil e Primária

ha sido la evolución histórica de los planteamientos educativos que han ido conformado la identidad cultural sorda, estrechamente unida a todo lo visual. El análisis de las relaciones que se establecen entre los métodos de enseñanza de lenguas y los recursos didácticos visuales asociados a las distintos enfoques ofrecerá algunas claves y distintos referentes de la memoria colectiva que podrán ser tenidos en consideración a la hora de establecer propuestas didácticas para la enseñanza/aprendizaje de lenguas a los niños sordos.

Los estudios desde el ámbito de conocimiento de la didáctica de las lenguas y culturas sobre la evolución de los métodos de enseñanza de idiomas son numerosos. Se trata, sin duda, de una temática que ha tenido una amplia trayectoria investigadora centrada exclusivamente en aprendices oyentes (Titone, 1968; Stern, 1983; Richards y Rogers, 1998; Christian Puren, 1988; Germain, 1993). Un aspecto abordado recientemente desde esta disciplina es el relacionado con la evolución de la metodología didáctica en los programas de enseñanza de lenguas dirigidos a personas con sordera en los contextos de España y Francia entre los siglos XVII y XX (Navarro, 2012).

Partiendo de los datos obtenidos en aquella investigación, a cuya breve descripción dedicaremos el primer apartado de esta comunicación, se presentarán las cuestiones metodológicas relacionadas con el estudio realizado en esta ocasión, poniendo de relieve los recursos didácticos visuales presentes en la muestra de programas representativos de los últimos cuatro siglos para la enseñanza de lenguas a sordos.

Finalmente, el análisis de los materiales y recursos visuales seleccionados dejará constancia de la importancia que los maestros de sordos de distintas épocas han atribuído a la construcción del saber y a la apropiación de las lenguas a través de la vista y de la mirada. El recorrido histórico permitirá la recuperación de la memoria y de los referentes visuales que conforman la cultura sorda. Conservarla y transmitirla a la infancia es cuestión de todos, familiares, educadores... pero solo el arte, en sus múltiples manifestaciones, puede inmortalizar sus valores.

\section{Programas de enseñanza de lenguas para sordos y recursos visuales}

\subsection{Contexto español}

Como paso previo a la elección y análisis de los recursos visuales que serán objeto de este estudio se hace necesario contar con una muestra de programas de enseñanza de lenguas para sordos. Con este fin, se ha tomado como referencia la selección intencionada de los distintos casos de estudio o programas de la tesis de Navarro (2011). Está formada por una veintena de programas de enseñanza de lenguas para sordos representativos de los contextos francés y español a lo largo del abanico temporal contemplado entre los siglos XVII y XX (50\% perteneciente a cada contexto). De acuerdo con las conclusiones recogidas en la investigación de partida, se han especificado para cada programa los datos del autor, la fecha de publicación y los métodos de enseñanza de lenguas de los que participan según la variable contextual.

Los programas que conforman la muestra del contexto de origen español son:
Programa 1. Redvction de las letras, y arte para enseñar a ablar los mvdos (Pablo Bonet, 1620). Método tradicional práctico.

Programa 2. Pronvnciaciones generales de lengvas (Baptista de Morales, 1623). Método tradicional teórico.

Programa 3. Escuela española de sordomudos ó Arte para enseñarles à escribir y hablar el idioma español (Hervás y Panduro, 1795). Método tradicional práctico.

Programa 4. Plan de enseñar a los sordo-mudos el idioma español (Hernández, 1815). Método tradicional teórico

Programa 5. Curso elemental de instrucción de sordo-mudos (Ballesteros y Fernández, 1845). Método tradicional teórico-práctico.

Programa 6. La enseñanza del sordomudo según el método oral (Barberá, 1895). Metodología directa (método oral, método intuitivo).

Programa 7. Método teórico-práctico de idioma para la enseñanza del mismo al sordomudo, por medio de la palabra hablada (Granell y Forcadell, 1928). Método ecléctico. 
$2^{\text {nd }}$ International Conference Art, Illustration and Visual Culture in Infant and Primary Education
Congresso Internacional

de Arte, llustração e Cultura Visual

na Educação Infantil e Primária

\subsection{Contexto francés}

\section{Cuestiones \\ metodológicas de la investigación}

\subsection{Objetivos}

Programa 8. Sordera profunda bilateral prelocutiva (Perelló y Tortosa, 1992). Método oral. Programa 9. Introducción a la Comunicación Bimodal (Alonso y otros, 1989). Enfoques comunicativos. Comunicación total.

Programa 10. Lenguaje de signos manuales (Perelló y Frigola, 1998). Enfoques bilingües (método pedagógico: lengua de signos/ lengua escrita).

En el contexto francés se han contemplado los recursos de los siguientes programas:

Programa 1. Cours élémentaire d’éducation des sourds et muets (Deschamps, 1776). Método tradicional teórico.

Programa 2. La véritable maniere d'instruire les Sourds et Muets (Épée, 1784). Método tradicional teórico-práctico.

Programa 3. Cours d'instruction d'un sourd-muet de naissance (Sicard, 1799). Método tradicional teórico-práctico.

Programa 4. Manuel d’enseignement pratique des sourds-muets (Bébian, 1827). Método práctico teórico.

Programa 5. Plan d'études. Programme de l'enseignement pour les écoles de sourds-muets non subventionnées par l'état (Valade-Gabel y Valade-Gabel, 1879). Metodología directa (método intuitivo)

Programa 6. Manuel de la phonomimie (Grosselin, 1881). Metodología directa (método activo, imitativo, repetitivo).

Programa 7. Premières leçons de choses et de langue française (Thollon, 1898). Metodología directa (método intuitivo).

Programa 8. Conseils aux sourds par un sourd, manuel de rééducation auditive par la parole et les sons musicaux (Lauer, 1920). Método oral

Programa 9. Manuel de lecture labiale (Istria y otros, 1992). Método audio-visual (SGAV)

Programa 10. La Langue de signes (Moody y otros, 1998). Educación bilingüe: LSF/francés escrito (método silencioso, TPR/método tradicional).

En los siguientes apartados se tratarán las cuestiones relacionadas con la investigación realizada, basada en el estudio histórico retrospectivo de documentos desde una metodología cualitativa. El estudio tiene una clara orientación histórico-descriptiva, didáctica y contrastiva, con la pretensión de contribuir a la recuperación de la memoria del patrimonio cultural visual de la cultura sorda y así posibilitar la creación y adaptación de recursos visuales adecuados a las necesidades de apropiación de las lenguas y culturas que configuran la identidad de esta comunidad.

El objetivo que persigue este trabajo es realizar el análisis histórico-descriptivo y contrastivo de los recursos visuales seleccionados de cada uno de los programas de enseñanza de lengua de la muestra de partida, con el máximo rigor científico-técnico.

Las preguntas que se plantean en el problema de investigación son:

1. ¿Qué características y finalidad tienen los recursos visuales que se encuentran en cada uno de los programas de la muestra?

2. ¿La presencia/ausencia de ciertos recursos visuales guarda relación con la metodología didáctica contemplada en los programas?

3. ¿Existen diferencias entre los recursos visuales seguidos en los programas publicados en España y Francia? ¿Cuáles son las dimensiones comunes en esos contextos?

Se trata pues de indagar en los programas para responder a las cuestiones referidas a la presencia/ausencia de ciertos recursos y su posible asociación a determinadas metodologías de enseñanza de lenguas; a las características y finalidad que se persigue con su empleo y, finalmente a las diferencias que se establecen en cuanto a la variable contextual. 
$2^{\text {nd }}$ International Conference Art, Illustration and Visual Culture in Infant and Primary Education $2^{\circ}$ Congreso Internacional

Arte, Ilustración y Cultura Visual en Educación Infantil y Primaria
Congresso Internacional

de Arte, Ilustração e Cultura Visual

na Educação Infantil e Primária

\subsection{Muestra}

Los recursos visuales presentes en la muestra de partida que han sido objeto de análisis en esta investigación se enumeran a continuación, clasificándolos según el contexto de origen de los programas.

\section{Contexto español:}

Programa 1. Apéndices documentales 1.1.3-1.1.6 (Navarro, 2012: 573-575)

Programa 2. Apéndices documentales 1.2.3-1.2.4 (Ibíd.: 581-582)

Programa 3. Apéndice documental 2.4.4 (Ibíd.: 602)

Programa 4. Apéndice documental 3.1.1 (Ibíd.: 615)

Programa 5. Apéndices documentales 3.3.2-3.3.4 (Ibíd.:626)

Programa 6. Apéndice documental 3.6.2 (Ibíd.: 638)

Programa 7. Apéndice documental 4.2.1 (Ibíd.: 655)

En el contexto francés, la muestra comprende:

Programa 1. Apéndices documentales 2.2.1-2.2.2 (Navarro, 2012: 591-592)

Programa 2. Apéndice documental 2.3.1 (Ibíd.: 595)

Programa 3. Apéndices documentales 2.5.2-2.5.4 (Ibíd.: 608-610)

Programa 4. Apéndices documentales 3.2.1-3.2.2 (Ibíd.: 619-620)

Programa 5. Apéndice documental 3.4.2 (Ibíd.:630)

Programa 6. Apéndice documental 3.5.1 (Ibíd.: 633)

Programa 7. Apéndice documental 3.7.1 (Ibíd.: 643)

Programa 8. Apéndice documental 4.1.2 (Ibíd.: 650)

\subsection{Recogida de datos $y$} tratamiento de la información

\section{Resultados de la investigación}

Con fundamento en la recogida de información sobre los recursos didácticos visuales contenidos en los programas de enseñanza de lenguas se ha empleado una parrilla u hoja de registro, con el propósito de sistematizar la información resultante del análisis documental realizado y que recoge los siguientes ítems: título del programa; año / siglo; localización (editorial y lugar de edición); lengua; contexto en el que se diseñó; fuentes y bibliografía recomendada; finalidad del recurso visual; metodología didáctica del programa y tipo de recursos (grabados, dibujos ilustración, fotografía; otros).

Con el horizonte puesto en responder a las cuestiones de investigación planteadas, una vez recopilada la información necesaria se procedió al tratamiento de la misma mediante el procedimiento de análisis pormenorizado del contenido. La información obtenida se ha analizado de forma individual, es decir, focalizada en cada uno de los programas; y de forma colectiva, realizando el contraste minucioso entre los programas, con la finalidad de responder globalmente a las cuestiones planteadas en esta investigación.

En cuanto a los recursos didácticos, se observa una progresión hacia el incremento del empleo de recursos visuales, primero del alfabeto manual o dactilológico a lo largo del periodo estudiado ya que es aceptado por todos los autores de los programas. También el lenguaje de signos naturales constituye un recurso visual importante en la mayoría de los programas analizados aunque en distintos programas se opte por las señas metódicas y en otros se niegue por completo el recurso a cualquier signo gestual. En segundo lugar, desde los inicios se recurre al dibujo y a las imágenes tanto de objetos como de las posiciones de los distintos órganos que intervienen en la articulación correcta de los distintos fonemas. En tercer lugar, se da el empleo de esquemas, láminas, viñetas. En efecto, la estimulación visual cobra paulatinamente más relevancia en los programas de enseñanza para personas con sordera analizados. Ello puede observarse en todos los programas de sendos contextos.

En cuanto a la modalidad comunicativa, se comenzó a emplear la modalidad viso-gestual, primero con la dactilología y después con los signos metódicos cuyo empleo se fue reduciendo dejando paso a los signos naturales o lenguas de signos de las comunidades sordas y que no tenían ninguna relación con los gestos que aceptaba el método directo. El congreso de Milán (1880) supone la supresión del empleo de los recursos que ponen en juego la modalidad viso- 


\section{Conclusión}

gestual, rechazándose el empleo de los signos en beneficio de la adquisición de la lengua oral. La modalidad viso-gestual sólo será retomada a partir del último tercio del siglo pasado, con los enfoques centrados en la filosofía de comunicación total y el reconocimiento de las lenguas de signos.

El estudio expuesto corrobora la idea de que la mayoría de las ideas actualmente consideradas como modernas o vanguardistas han sido ya postuladas o defendidas por los educadores de sordos en el pasado. La naturaleza misma ha marcado la vía a seguir desde que se consideraron las posibilidades educativas de estas personas. El principio es simple: la suplencia de unos sentidos por otros, la vista en lugar del oído, la vía secreta por donde entrar y camino llano por donde salir, hacer entrar por la ventana lo que no cabe por la puerta... Para conseguir este fin, los objetos, las imágenes y todo tipo de representaciones y recursos tanto arcaicos como tecnológicos: el éxito radicó siempre en que fueran visuales, los únicos capaces de configurar la identidad y la cultura sorda.

Germain, C. (1993). Évolution de l'enseignement des langues: 5000 ans d' histoire. Paris: CLE International. Navarro Rincón, A. (2011). La enseñanza de idiomas a sordos. Estudio de programas en España y Francia (XVII-XX). Tesis doctoral. Universidad de Granada.

Puren, $\mathrm{CH}$. (1988). Histoire des méthodologies de l'enseignement de langues. Paris: CLE International.

Richards, J. C. y Rodgers, T. S. (1998). Enfoques y métodos en la enseñanza de idiomas. Madrid: Cambridge University Press.

Stern, H. H. (1983). Fundamental Concepts of Language Teaching. Oxford: Oxford University Press.

Titone, R. (1968). Teaching Foreign Languages: An Historical Sketch.Washington, D. C.: George-town University Press. 